\title{
Microstructure and Mechanical Properties of WC-Co Reinforced With NbC
}

\author{
Wilson Acchar $^{\mathrm{a} *}$, Cordt Zollfrank ${ }^{\mathrm{b}}$, Peter Greil \\ a Department of Physics, Federal University of Rio Grande do Norte, \\ 59072-970 Natal - RN, Brazil \\ ${ }^{\mathrm{b}}$ Department of Materials Science (III), Glass and Ceramics, \\ University of Erlangen-Nürnberg, D-91058 Erlangen, Germany
}

Received: November 19, 2003; Revised: March 21, 2004

\begin{abstract}
Cemented carbides such as tungsten carbide-cobalt WC-Co composites have been widely used as cutting tool materials. Several reports have shown the influence of different factors such as grain size, type and amount of binder phase and the addition of hard particles on the properties of WC-Co. The purpose of this work was to investigate the effect of niobium carbide on the microstructure and mechanical properties of WC-Co. Specimens of WC-Co reinforced with NbC were mixed and subsequently hot-pressed in a inert atmosphere. The WC-Co-NbC composite material exhibited high hardness values $(18.9 \mathrm{GPa})$, flexural strength $(2100 \mathrm{MPa})$ and fracture toughness $\left(11.2 \mathrm{MPa} \cdot \mathrm{m}^{1 / 2}\right)$. TEM analysis has shown a bimodal grain size distribution of WC.
\end{abstract}

Keywords: tungsten carbide, hardness, fracture toughness, niobium carbide, microstructure

\section{Introduction}

Cemented carbides such as WC-Co and WC-Co-TiC are the most widely used material for metalworking ${ }^{1}$. As a consequence, a considerable amount of research effort has been spent to develop alternatives cemented carbide systems in order to improve the microstructure and mechanical properties of these materials. Figure 1 shows the influence of $\mathrm{TaC}(\mathrm{NbC})$ addition on the mechanical performance of $\mathrm{WC}^{2}$. The hardness decreases only slightly with increasing $\mathrm{TaC}(\mathrm{NbC})$ content, but the decrease in transverse-rupture strength is remarkably high for $\mathrm{TaC}(\mathrm{NbC})$ contents exceeding 20 wt. (\%). Recent studies have shown an increase in hardness and fracture toughness of WC through the use of different binding phases and the synthesis of nanocomposites ${ }^{3,6}$. The addition of some hard refractory particles such as TiC, $\mathrm{VC}$ and $\mathrm{Mo}_{2} \mathrm{C}$ has produced a pinning effect, reducing the grain growth of the WC-Co matrix ${ }^{3,7,8}$, which contributes to the final properties of the composite material. Literature data about the use of $\mathrm{NbC}$ in $\mathrm{WC}$ is still scant. Brazil holds the main world niobium reserves, making the study on possible application of niobium very strategic.

On the other hand, $\mathrm{WC}$ and $\mathrm{NbC}$ have also been reported as reinforcement in alumina matrix, due its high hardness and elastic modulus ${ }^{9}{ }^{10}$. Hot-pressed alumina reinforced with $\mathrm{NbC}$ has caused an increase of the hardness and fracture toughness from $16.5 \mathrm{GPa}$ and $2.9 \mathrm{MPa} . \mathrm{m}^{1 / 2}$ to $19.0 \mathrm{GPa}$ and 4.2 MPa. $\mathrm{m}^{1 / 2}$, respectively.

The objective of this work was to study the influence of $\mathrm{NbC}$ on the microstructure and mechanical properties of hot-pressed WC-Co composite material.

\section{Experimental Procedure}

The starting powders used in this work consisted of WC (Wolfram Bergbau, Austria), with D50 $=1 \mu \mathrm{m}$ and $10 \mathrm{wt}$. (\%) of cobalt powder as binder phase. Niobium carbide (Herman Starck Berlin) with D50 $=2.3 \mu \mathrm{m}$ was used as reinforcing element. The WC and Co powders were mixed with $2 \mathrm{wt}$. (\%) of $\mathrm{NbC}$, homogenized for four hours in a planetary ball mill and uniaxially hot-pressed at $1250{ }^{\circ} \mathrm{C}$ during $1 \mathrm{~h}$ under a pressure of $20 \mathrm{MPa}$ in flowing argon. Microstructural analysis was carried out on sintered samples in a transmission electron microscope (TEM, Philips, CM 30) operated at $300 \mathrm{kV}$. Energy dispersive X-ray spectrometry (EDS) was

*e-mail: acchar@dfte.ufrn.br 
performed using a SiLi-detector (type 7370, ISIS 30, Link, Oxford) attached to the TEM. Hardness and fracture toughness were determined using a Vickers hardness testing machine by using the method of Shetty et al. ${ }^{11}$. The analysis of crystalline phases was determined by $\mathrm{X}$-ray diffraction.

\section{Results and Discussion}

The X-ray powder diffraction pattern of pure and reinforced WC-Co solely showed the presence of WC and Co phases (Table 1). No peaks of NbC or other crystalline reaction product phases were identified. The addition of $\mathrm{NbC}$ to WC-Co system seems to promote the formation of a carbide phase that contains both $\mathrm{W}$ and $\mathrm{Nb}$, possibly $(\mathrm{W}, \mathrm{Nb}) \mathrm{C}$. The atomic radii of $\mathrm{W}(140 \mathrm{pm})$ and $\mathrm{Nb}(146 \mathrm{pm})$ are nearly the same. Thus, the NbC may be dissolved within the WCphase due to substitution of $\mathrm{W}$ by $\mathrm{Nb}$. There is no (W-Nb)C phase diagram published in the literature. There are well known phase diagrams that show the mutual solubility of $(\mathrm{Nb}, \mathrm{gU}),(\mathrm{V}, \mathrm{Nb}),(\mathrm{bTi}, \mathrm{Nb}),(\mathrm{Ti}, \mathrm{V}),(\mathrm{Ti}, \mathrm{W})$ and $(\mathrm{Cr}, \mathrm{W})^{12}$ and $\mathrm{Nb}-\mathrm{W}^{13}$.

Similar behavior was also observed in alumina reinforced with $(\mathrm{Ti}, \mathrm{W})$ carbides ${ }^{14}$. The results indicated the formation of a solid solution of (Ti-W)C, which corresponds to the Ti-W binary phase diagram ${ }^{14}$. Hot-pressing resulted in dense materials, with fraction densities in the range from 98.5 to $99.0 \%$ theoretical density (Table 1). Similar densities have been reported for hot-pressed alumina-NbC composites $^{15}$.

Figure 2 shows the mechanical properties of WC-Co and WC-Co-NbC composites investigated in this work. For comparison, the hardness and fracture toughness of $\mathrm{Al}_{2} \mathrm{O}_{3}$

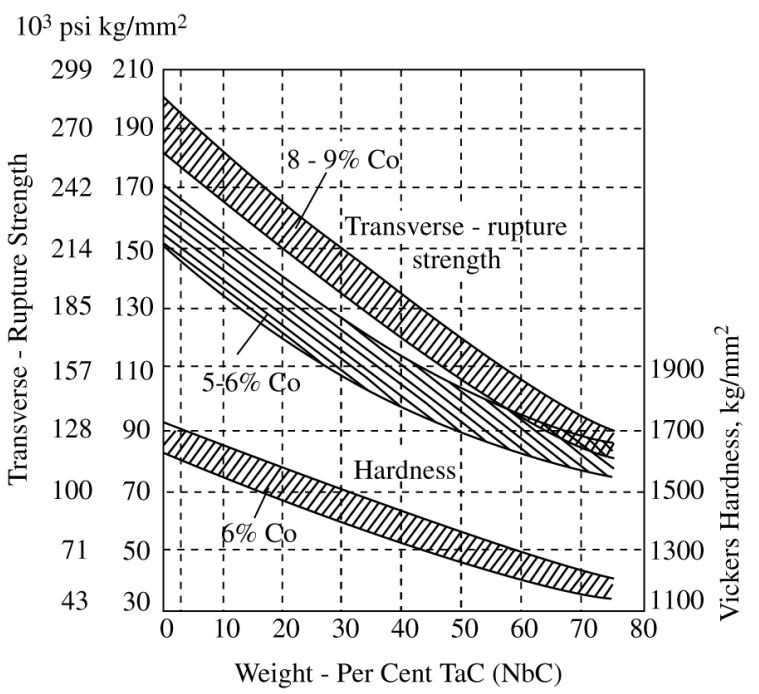

Figure 1. Mechanical properties of WC-Co with $\mathrm{TaC}-\mathrm{NbC}^{11}$. and WC-Co reinforced with hard particles are also presented in Fig. 2. The mechanical properties of WC-Co-NbC material are comparable to those of the reinforced materials available in the literature. The introduction of $\mathrm{NbC}$ into WC-Co cemented carbide resulted in a slight decrease of fracture toughness from 12 to $11.2 \mathrm{MPa} \cdot \mathrm{m}^{1 / 2}$. The addition of $\mathrm{NbC}$ to the WC-Co composite caused practically no effect on the hardness values as compared to pure WC-Co. The Hv-values of the WC-Co-NbC material remained almost the same as that for the WC-Co copmosite (19 GPa). The addition of different types of reinforcing elements did not influence considerably the fracture toughness values of WC-Co. $\mathrm{K}_{\mathrm{IC}}$ values vary from 10.2 to $12 \mathrm{MPa} \cdot \mathrm{m}^{1 / 2}$. Figure 2 shows that the hardness is improved when $\mathrm{WC}$ is incorporated in alumina. The alumina-WC composite material exhibits a hardness value of $21 \mathrm{GPa}$, slightly higher than WC-Co reinforced material ${ }^{15}$.

Introduction of $\mathrm{TiC}$ and $\mathrm{TiC}+\mathrm{Mo}_{2} \mathrm{C}$ into WC-Co cemented carbide results in a drastic decrease in the hardness from 19 to $14 \mathrm{GPa}$. Substitution of TiC by NbC improves the hardness of WC-Co material. Further increase in hardness is observed when $\mathrm{VC}$ is added to the system. The hardness of a WC-composite material depends strongly on the processing method and the grain size of the raw materials ${ }^{3,6,7}$. This dependence can explain the variation in hardness values of the different WC-Co composites, presented in Fig. 2.

Table 1. Mechanical properties and crystalline phases of WC-Co$\mathrm{NbC}$ sintered specimens.

\begin{tabular}{lcc}
\hline \multicolumn{1}{c}{ Properties } & WC-Co & WC-Co-NbC \\
\hline Theoretical Density (\%) & 99.0 & 98.5 \\
Flexural Strength (MPa) & $2000 \pm 220$ & $2100 \pm 200$ \\
Crystalline Phases & WC, Co & WC, Co \\
\hline
\end{tabular}

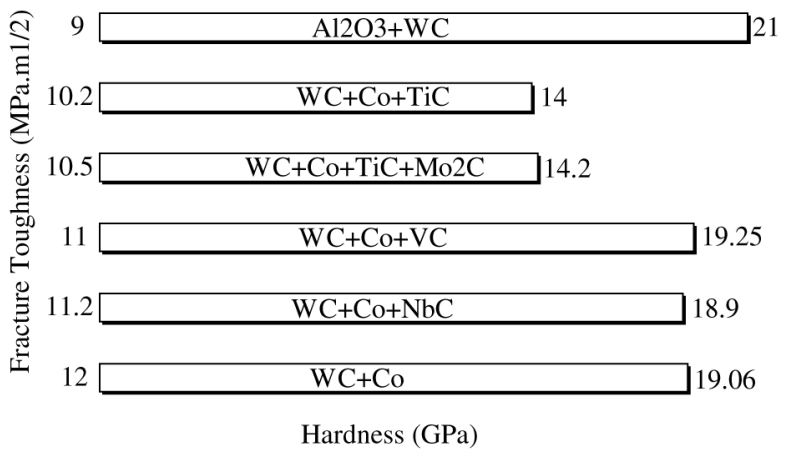

Figure 2. Comparison of hardness and fracture toughness values from various different WC-materials ${ }^{2-6,8,14}$. 
TEM investigation was used to observe the morphological aspects and the microstructure of WC-Co- $\mathrm{NbC}$ composites. The composite ceramic material exhibited a heterogeneous microstructure with a bimodal WC-grain size distribution (Figs. 3a and 3b). The microstructure consisted of large $(1 \mu \mathrm{m})$ and fine $(100-200 \mathrm{~nm})$ grains of WC. The WC-particles were analyzed by EDS (Fig. 3c). The main elements found in the spectra were W, Co and $\mathrm{Fe}$, whereas $\mathrm{Nb}$ was only hardly detectable (see inset in Fig. 3c). The results obtained by EDS indicate that the

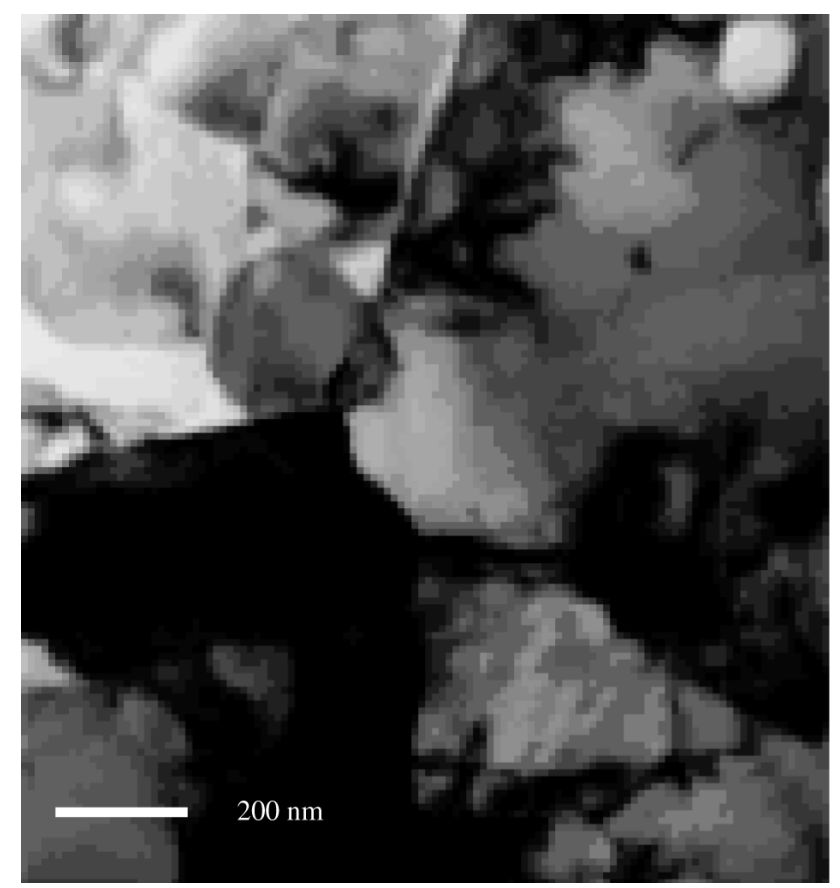

(a) particles formed were principally composed of WC. A typical STEM image and a EDS line scan with element distribution of $\mathrm{W}, \mathrm{Co}, \mathrm{Nb}, \mathrm{C}$, and Fe is given in Fig. 4. The results suggest that the dark phase consisted primarily of tungsten and carbon (WC) and the bright phase of $\mathrm{Co}$ and $\mathrm{Fe}$, respectively. The presence of niobium was not detected, possibly due the small amount of this element in the analyzed region.

Figure 5 shows EDS maps of the spatial distribution of the elements within the analyzed region. The region in-

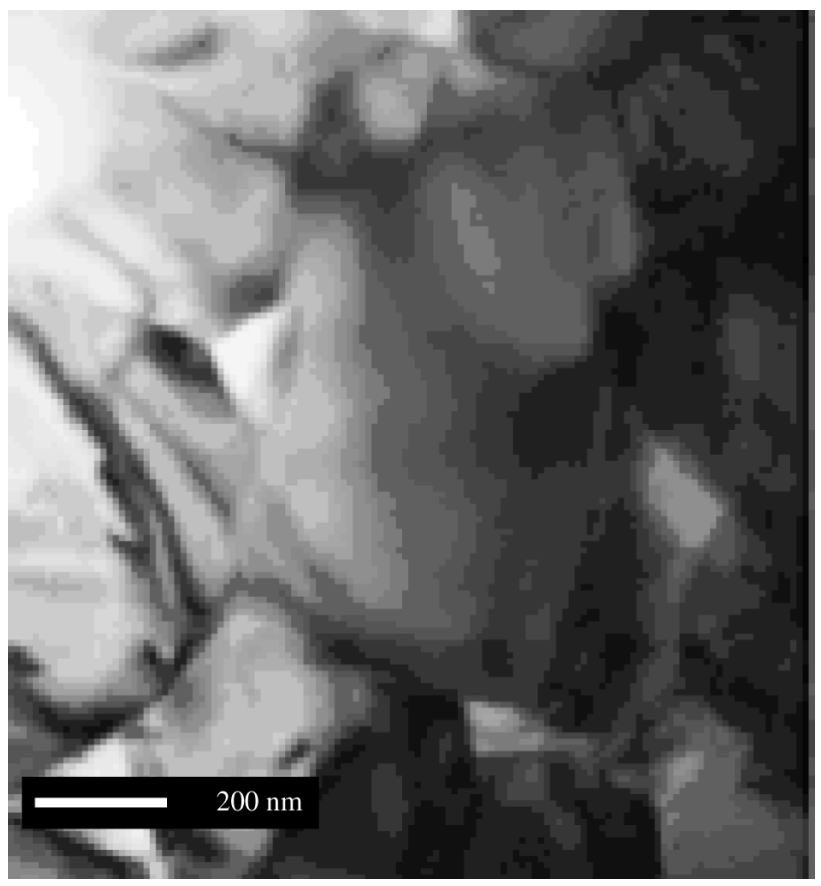

(b)

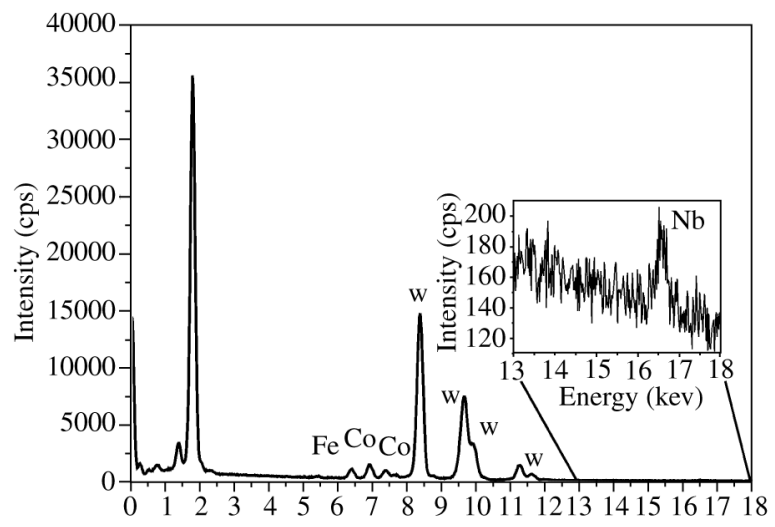

(c)

Figure 3. a) and b) TEM micrographs of WC-Co-NbC composites; c) EDS analysis of the WC-Co-NbC composites in the TEM. 
vestigated was the same of Fig. 4. The observed data confirm that the dark grains correspond to $\mathrm{W}$ and very small amounts of $\mathrm{Nb}$ and the bright region basically to $\mathrm{Co}$ and

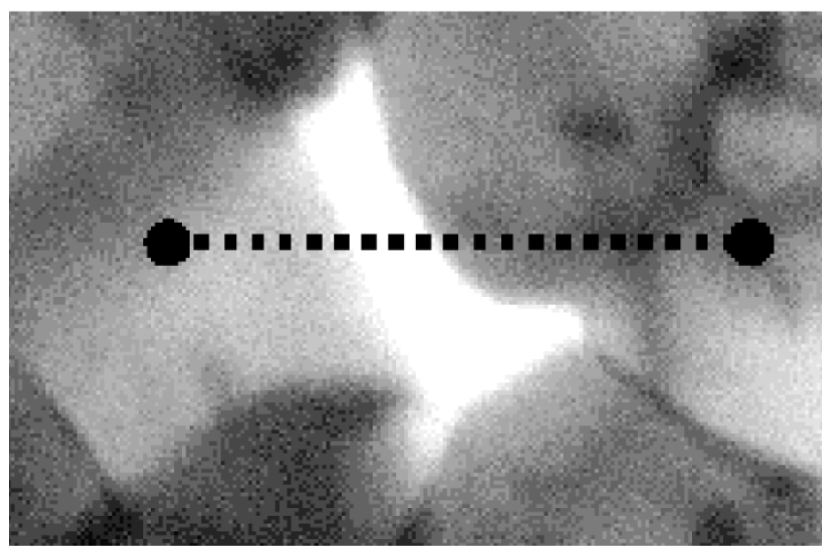

(a)
Fe. The $\mathrm{Nb}$ appears to be equally distributed over the analyzed region suggesting the formation of $(\mathrm{W}, \mathrm{Nb}) \mathrm{C}$. The results obtained in this work indicated that the WC-Co-

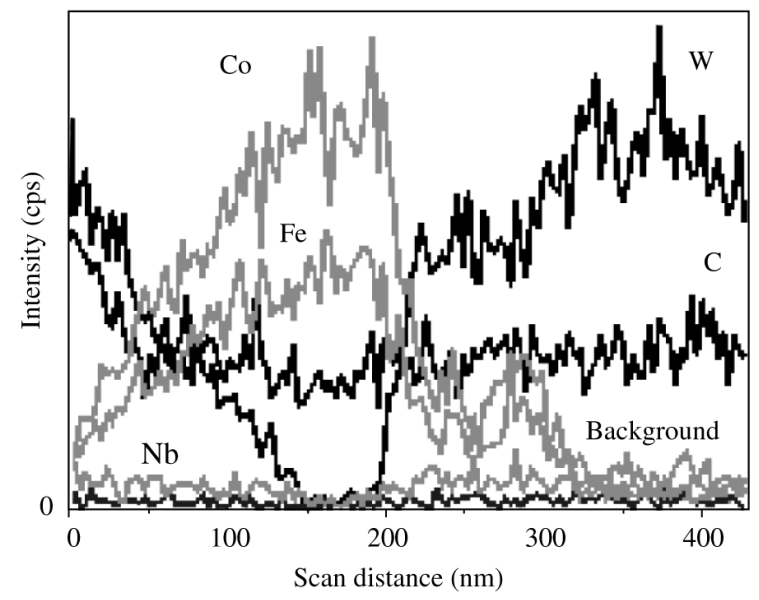

(b)

Figure 4. STEM image and corresponding EDS line scan.

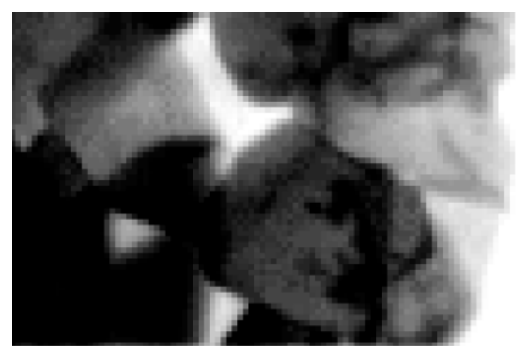

(a)

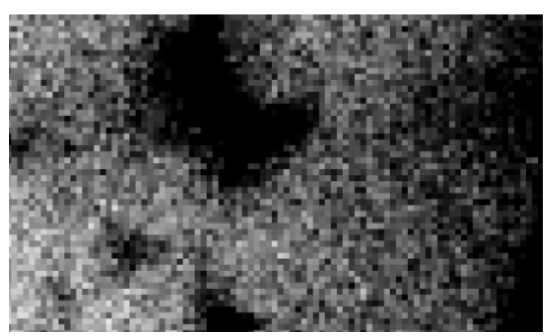

(d)

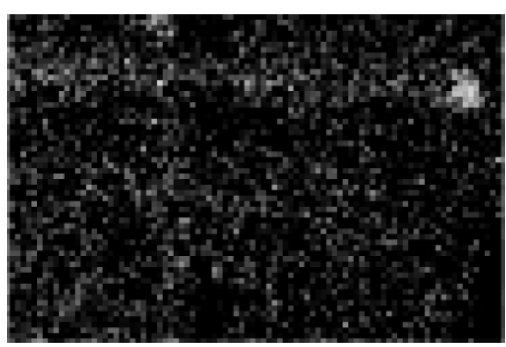

(b)

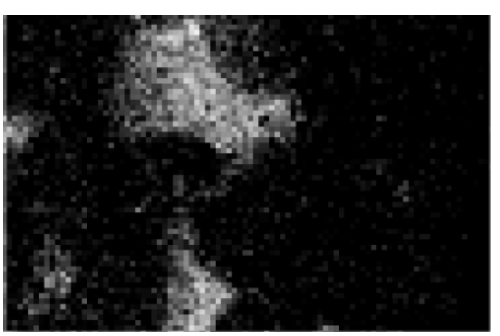

(e)

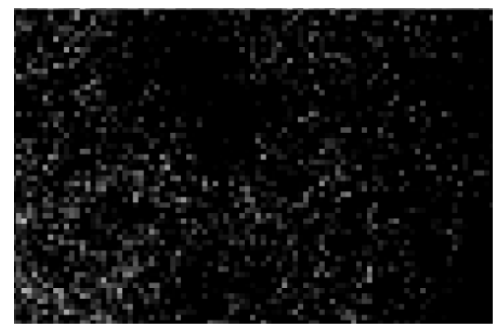

(g)

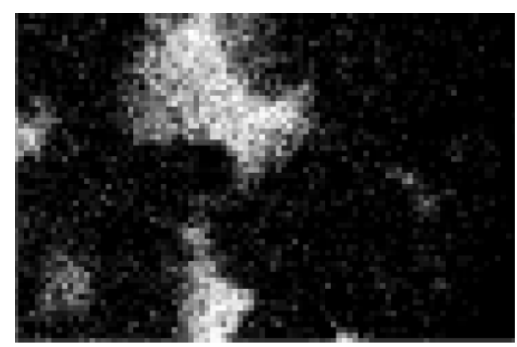

(c)

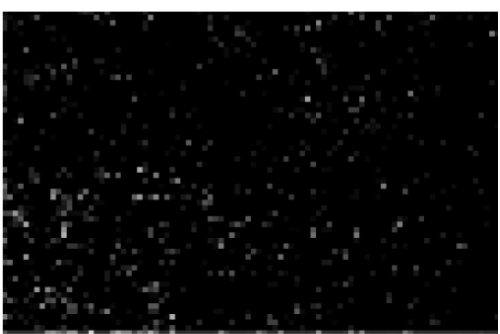

(f)

Figure 5. STEM image and EDS maps of $\mathrm{W}, \mathrm{Co}, \mathrm{Nb}, \mathrm{C}$ and $\mathrm{Fe}$. 
$\mathrm{NbC}$ ceramic composites show a good potential to be developed. Further investigation is still under way to study the dependence of higher niobium carbide content on the microstructure and mechanical performance of $\mathrm{NbC}$-reinforced WC-Co.

\section{Conclusions}

Dense specimens of WC-Co-NbC were fabricated by hot-pressing. No $\mathrm{NbC}$ or other new $\mathrm{Nb}$-phases were detected by X-ray diffraction. The addition of $\mathrm{NbC}$ to the WC-Co system seems to promote the formation of a carbide phase that consisted of tungsten and niobium $(\mathrm{W}, \mathrm{Nb}) \mathrm{C}$.

Incorporation of $2 \mathrm{wt}$. (\%) $\mathrm{NbC}$ into WC-Co cemented carbide produced a composite material with mechanical properties comparable to the other cemented carbides systems, suggesting that the composite can be a good candidate to metalworking. TEM micrographs have shown a microstructure consisting of large and fine grains of tungsten carbide.

\section{Acknowledgment}

Part of this work was carried out at the Central Facility for High-Resolution Electron Microscopy of the University of Erlangen-Nürnberg, Germany.

\section{References}

1. Bradt, G. Mater.Technology v. 14, n. 1, p. 17-24, 1999.

2. Kopf, P.S.; Kieffer,R.; Cemented Carbides, The Macmillan
Company, p. 188-198, 1960.

3. Schubert, W.D.; Bock, A.; Lux, B. Int.J.of Refractory \& Hard Mater v. 13, p. 281-296, 1995.

4. Bhaumik, S.K.; Balasubramaniam, R.; Upadhyaya, G.S.; Vaidya, M.L.; J.Mater.Sci.Lett, v. 11, p. 1457-59, 1992.

5. Zhu, Y.T.; Manthiran, A. J.Amer. Ceram.Soc., v. 77, n. 10, p. 2777-78, 1994

6. Leiderman, M.; Botstein, O. A Rosen, Proceeding of the $4^{\text {th }}$ European Conference on Advanced Materials and Process, Italy, September 1995.

7. Bhaumik, S.K.; Upadhyaya, G.S.; Vaidya, M.L. Mater.Sci.Tech, v. 7, p. 723-27, 1991.

8. Sepulveda, R.; Arenas, F. Inter. J. Refract.\&Hard Mater. v. 19, p. 389-396, 2001.

9. Acchar, W.; Martinelli, A.E.; Vieira, F.A.; Cairo, C.A. Mat. Sci. Eng. v. 284, p. 84-87, 2000.

10. Pasotti, M.R.; Bressiani, A.H.; Bressiani, J.C. Inter. J. Refrac.\&Hard Mater. v. 16, p. 423-27, 1998.

11. Shetty, D.K.; Wrigth, I.G.; Mincer, P.N.; Clauer, A.H. J. Mater. Sci, v. 20, p. 1873-82, 1985.

12. Murray, J.L. Bull.Alloy Phase Diagram v. 2 n. 2, 1981.

13. Metals Handbook, ed. 5, v. 8, p. 284, 1973.

14. Acchar, W.; Fonseca, J.L. Mater. Sci. Eng A., v. 371, p. 382-387, 2004.

15. Acchar, W.; Greil, P.; Martinelli, A.E.; Cairo, C.A.; Bressiani, A.H.; Bressiani, J.C. J. Europ. Ceram. Soc, v. 20, p. 1765-69, 2000.

16. Weon-Pil Tai, Watanab, T. J. Am. Ceram. Soc, v. 81, n. 6, p. 1673-76, 1998. 